\title{
Physical assessment ability of nurses and midwives on maternal care in Mongolia
}

\author{
Sakumi Akao ${ }^{1^{\star}}$, Keiko Tanabe ${ }^{1}$, Bayarkhuu Dorjsuren $^{2}$, Michiyo Higuchi $^{3}$ \\ ${ }^{1}$ Department of Nursing, Nagoya University Graduate School of Medicine, Nagoya, Japan; \\ *Corresponding Author: akao@met.nagoya-u.ac.jp \\ ${ }^{2}$ Mongolian Nurses Association, Ulaanbaatar, Mongolia \\ ${ }^{3}$ Department of Public Health and Health Systems, Nagoya University Graduate School of Medicine, Nagoya, Japan
}

Received 18 January 2013; revised 20 February 2013; accepted 3 March 2013

\begin{abstract}
This study examined the physical assessment ability of Mongolian nurses and midwives engaged in maternal care and the factors that could influence this ability. We found that nurses and midwives from prefectural hospitals had higher scores than those from national and district (soum) hospitals. The latter group could not perform more than half of the 28 tested procedures on their own, even though most had over 10 years' experience. Therefore, to decrease the Mongolian maternal mortality ratio, we argue that in-service training for nurses and midwives in both the capital city and peripheral areas is needed.
\end{abstract}

Keywords: Physical Assessment; Mongolian

Nurses and Midwives; Skilled Birth

Attendant; Maternal Mortality Ratio

\section{INTRODUCTION}

Mongolia, a lower-middle-income country with the world's lowest population density, has seen a decrease in its maternal mortality ratio (MMR) from 93.0 per 100,000 births in 2000 to 65.0 by 2008 [1]. This decrease is largely due to the government's efforts and international contributions. In 2007, 99.8\% of pregnant women visited antenatal clinics in Mongolia and $83.7 \%$ went through at least six antenatal check-ups, which is the recommended number of sessions in Mongolia; also, almost $100 \%$ of Mongolian women were literate [2], according to the Ministry of Health. In addition, $99.6 \%$ of child births in Mongolia were assisted in health facilities with basic or comprehensive emergency obstetric and newborn care, satisfying the guidelines for emergency obstetric care [3]. However, although maternal health service coverage resembles that of high-income countries, the MMR in Mongolia still seems high compared to countries that have similar coverage, such as Japan and the Republic of Korea, where MMR is 6 and 18 per 100,000 births, respectively [1]. If a woman is attended by skilled birth attendant after receiving sufficient antenatal care [2] and nevertheless loses her life during childbirth, the skill and knowledge of the health personnel in question should be considered as a possible factor in this outcome, as well as economic and geographic issues. Therefore, against the background data presented above, this study aims to evaluate the physical assessment (PA) ability of nurses and midwives for maternal care in Mongolia, and to investigate the factors that could influence this ability.

\section{METHODS}

\subsection{Study Design}

We conducted a cross-sectional study and distributed a questionnaire to nurses and midwives who work in maternal care at different levels of hospital.

\subsection{Sampling Frame}

We targeted three different hospital levels: national hospitals, which provide tertiary-level health services with specialized maternal care; prefectural hospitals, which provide secondary-level health services; and district (soum) hospitals, which provide primary-level health services. All national hospitals are located in the capital city, Ulaanbaatar, while the prefectural and soum hospitals are located outside the capital city. Two national hospitals, two prefectural hospitals, and a number of soum hospitals were selected by the Mongolian Nurses Association to participate in this study.

In 2009, members of the Mongolian Nurses Association distributed the questionnaires to 300 nurses and midwives, garnering 168 valid responses. Since general wards are the only wards in most soum hospitals, we did not restrict responses to obstetric wards but included all nurses who work in hospitals with pregnant women and all midwives. 
We provided potential participants with written information on the purpose and procedures of the study and obtained oral consent from them. The Ethics Committee of Nagoya University Graduate School of Medicine approved the study protocol.

\subsection{Questionnaire}

The questionnaire assessed participants' backgrounds and self-rated ability on 28 items representing practices often used in perinatal care to examine the condition of a pregnant woman and her child. We modified the method from a previous study [4]. Of the 28 items, 13 were considered to refer to antenatal care, 8 as delivery care, and 7 as neonatal care. We asked participants to rate their ability to perform each item on a scale of 1 to $5(1=u n-$ familiar, 2 = barely familiar, 3 = familiar but unable to perform alone, $4=$ able to perform alone, and $5=$ able to perform alone and teach). A score of 4 or higher was considered an adequate level of skill.

\subsection{Data Analysis}

We classified the 168 nurses and midwives according to type of workplace: national hospital, prefectural hospital, or soum hospital. Among these three groups, we compared the ratios of participants who had a score of 4 or more in each of the $28 \mathrm{PA}$ items. We then divided the items into three forms of care: antenatal care, delivery care, and neonatal care. We determined crude odds ratios (ORs) by categorizing participants with a high score (over $80 \%$ of total points) for each form of care as dependent variables, and workplace, length of clinical experience, and professional category as independent variables. We determined crude as well as adjusted ORs by logistic regression analysis. Length of clinical experience was categorized as less than 15 years, greater than 15 but less than 20 years, or greater than 20 years. The professional categories were "nurse" and "midwife".

Data analysis was conducted using SPSS version 17. Any $p<0.05$ was considered statistically significant.

\section{RESULTS}

Of the 168 nurses and midwives, 54 worked for national hospitals, 40 for prefectural hospitals, and 74 for soum hospitals. The background data of the participants are shown in Table 1.

With regard to length of clinical experience, a significant difference was observed between national and prefectural hospitals. The ratio of midwives to nurses also differed significantly between the three types of workplaces.

Figure 1 compares the ratio of participants with high PA ability between the three types of workplaces. Scores were derived from self-evaluation; a score of 4 or higher
Table 1. Participant characteristics.

\begin{tabular}{ccccc}
\hline & $\begin{array}{c}\text { National } \\
\text { hospitals }\end{array}$ & $\begin{array}{c}\text { Prefectural } \\
\text { hospitals }\end{array}$ & $\begin{array}{c}\text { Soum } \\
\text { hospitals }\end{array}$ & p-value \\
\hline $\mathrm{n}$ & 54 & 40 & 74 & \\
$\begin{array}{c}\text { Length of clinical } \\
\text { experience (years) }\end{array}$ & $20.8 \pm 8.4^{*}$ & $16.6 \pm 7.7^{*}$ & $18.2 \pm 11.6$ & 0.042 \\
$\begin{array}{c}\text { Range } \\
\text { Professional } \\
\text { category }\end{array}$ & $2-36$ & $4-31$ & $1-38$ & \\
$\begin{array}{c}\text { Registered nurse } \\
\text { Midwife }\end{array}$ & $15(27.8 \%)$ & $2(5 \%)$ & $58(78.4 \%)$ & \\
\hline
\end{tabular}

Mean \pm SD, n (\%).

was considered to indicate high PA ability. Out of the three types of workplaces, prefectural hospitals had the highest ratio of participants with high ability in 25 of the $28 \mathrm{PA}$ items. The number of PA items that received a score of 4 or higher from more than $50 \%$ of the participants scoring high in PA ability was remarkably different between the three types of workplace: for national hospitals, it was 10 items, for prefectural hospitals 23 items, and for soum hospitals 14 .

Table 2 shows the ORs of high PA ability scores across backgrounds. Participants working at prefectural hospitals had significantly higher Ors than did those working at national hospitals for each form of care, while national hospitals and soum hospitals showed no significant difference. With regard to length of clinical experience, there was no significant difference between the participants. In the professional category, midwives showed significantly higher ORs than nurses for antenatal care and delivery care after a univariate analysis; however, an adjusted analysis found no significant difference between the forms of care.

Table 3 presents the ORs of high PA ability scores among midwives by background. By type of workplace, prefectural hospitals showed significantly higher ORs than did national hospitals for antenatal and neonatal care, and soum hospitals showed significantly lower ORs than did national hospitals for delivery care. With regard to length of clinical experience, midwives with the longest clinical experience-more than 20 years-showed significantly lower ORs for antenatal and neonatal care than did the group with the least experience.

\section{DISCUSSION}

In this study, the PA ability of nurses and midwives for maternal care was found to differ between the three hospital levels. Contrary to our predictions, midwives and nurses who worked at national hospitals specializing in maternal care and those who had longer clinical experience did not have significantly higher PA abilities. We 


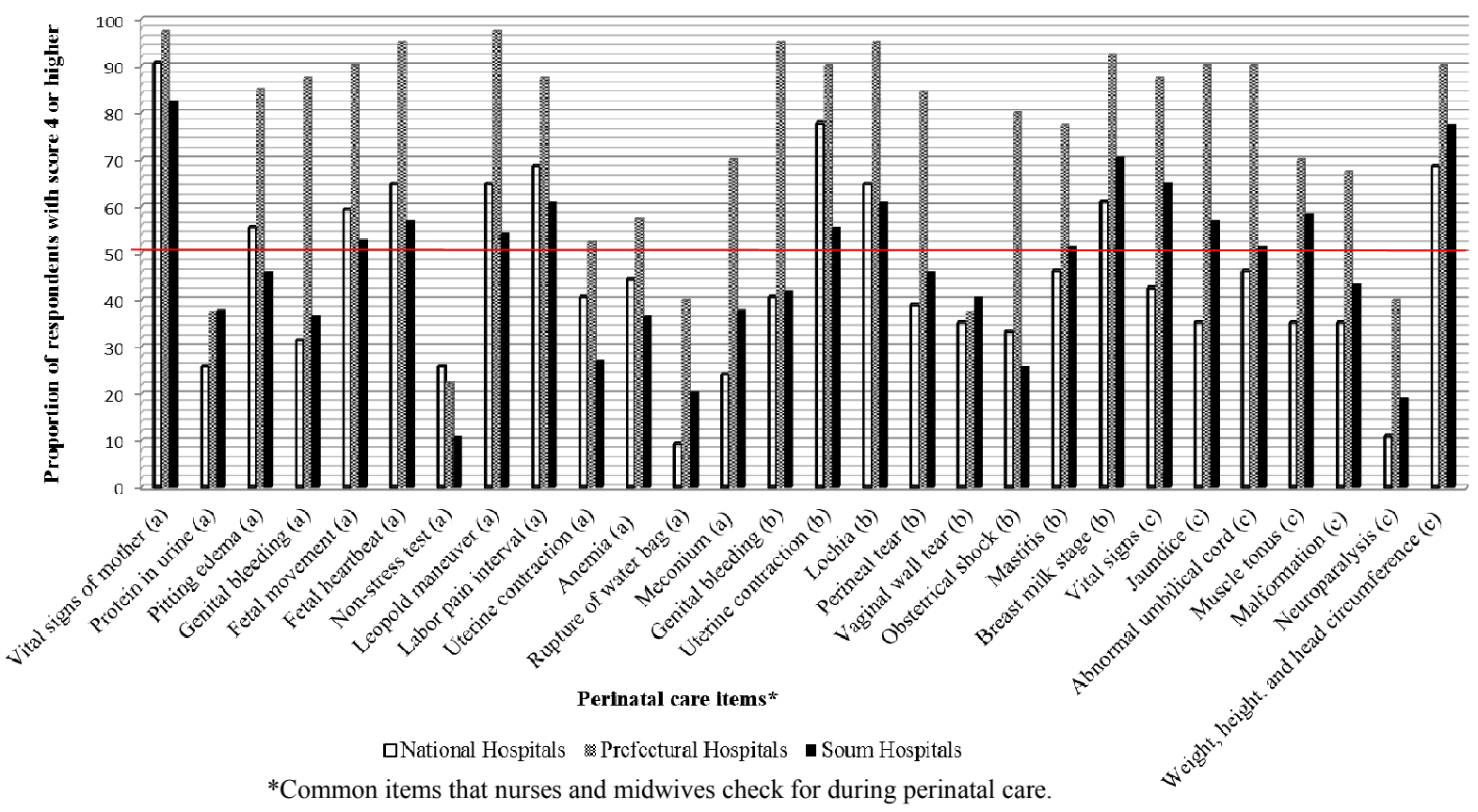
(a) for antenatal care
(b) for delivery care
(c) for neonatal care

Figure 1. Participants with high PA ability by item and hospital level.

Table 2. Physical assessment ability with $>80 \%$ score among nurses and midwives.

\begin{tabular}{|c|c|c|c|c|c|c|c|}
\hline \multirow[b]{2}{*}{ Variable } & \multirow[b]{2}{*}{$\mathrm{n}$} & \multicolumn{2}{|c|}{ Antenatal care } & \multicolumn{2}{|c|}{ Delivery care } & \multicolumn{2}{|c|}{ Neonatal care } \\
\hline & & $\begin{array}{l}\text { Crude OR } \\
(95 \% \mathrm{CI})\end{array}$ & $\begin{array}{l}\text { Adjusted OR } \\
(95 \% \mathrm{CI})\end{array}$ & $\begin{array}{l}\text { Crude OR } \\
(95 \% \mathrm{CI})\end{array}$ & $\begin{array}{l}\text { Adjusted OR } \\
(95 \% \mathrm{CI})\end{array}$ & $\begin{array}{l}\text { Crude OR } \\
(95 \% \mathrm{CI})\end{array}$ & $\begin{array}{l}\text { Adjusted OR } \\
(95 \% \mathrm{CI})\end{array}$ \\
\hline \multicolumn{8}{|l|}{ Workplace } \\
\hline National hospital & 54 & 1.00 & 1.00 & 1.00 & 1.00 & 1.00 & 1.00 \\
\hline Prefectural hospital & 40 & $4.55(2.16-9.61)^{* *} 8$ & $8.88(2.94-26.85)^{* *}$ & $1.73(0.98-3.07)$ & $3.04(1.22-7.56)^{*}$ & $2.50(1.32-4.77)^{* *}$ & $5.82(2.19-15.47)^{* *}$ \\
\hline Soum hospital & 74 & $1.32(0.57-3.06)$ & $1.21(0.33-4.34)$ & $0.79(0.43-1.44)$ & $0.45(0.19-1.08)$ & $1.42(0.72-2.79)$ & $1.36(0.49-3.76)$ \\
\hline \multicolumn{8}{|l|}{$\begin{array}{l}\text { Length of clinical } \\
\text { experience (years) }\end{array}$} \\
\hline 15 & 52 & 1.00 & 1.00 & 1.00 & 1.00 & 1.00 & 1.00 \\
\hline $16-19$ & 40 & $0.77(0.37-1.60)$ & $1.44(0.51-4.11)$ & $1.07(0.55-2.09)$ & $1.19(0.47-2.98)$ & $0.86(0.43-1.70)$ & $1.26(0.49-3.19)$ \\
\hline $20 \leq$ & 76 & $0.29(0.15-0.56)^{* *}$ & $0.45(0.16-1.27)$ & $0.97(0.57-1.66)$ & $1.19(0.53-2.67)$ & $0.42(0.23-0.76)^{* *}$ & $0.59(0.25-1.38)$ \\
\hline \multicolumn{8}{|l|}{$\begin{array}{l}\text { Professional } \\
\text { Categories }\end{array}$} \\
\hline Registered nurse & 75 & 1.00 & 1.00 & 1.00 & 1.00 & 1.00 & 1.00 \\
\hline Midwife & 93 & $3.32(1.46-7.57)^{* *}$ & $1.35(0.41-4.47)$ & $2.41(1.28-4.56)^{* *}$ & $1.03(0.44-2.42)$ & $1.83(0.93-3.59)$ & $1.01(0.38-2.64)$ \\
\hline
\end{tabular}

${ }^{*} \mathrm{p}<0.05,{ }^{* *} \mathrm{p}<0.01$.

found that the PA ability of nurses and midwives, except for those in prefectural hospitals, was generally inadequate, as indicated by the majority of participants, who reported that they were unable to perform many procedures by themselves.

The observation that midwives and nurses working at prefectural hospitals had higher PA abilities than those working at national hospitals may be due to unbalanced physician distribution and/or divisions of tasks between occupations. While the number of obstetricians and gynecologists in Ulaanbaatar is 3.2 per 1000 people, peripheral areas outside Ulaanbaatar only have $1.5 \mathrm{ob} / \mathrm{gyns}$ 
Table 3. Physical assessment ability with $>80 \%$ score among midwives.

\begin{tabular}{|c|c|c|c|c|c|c|c|}
\hline \multirow[b]{2}{*}{ Variables } & \multirow[b]{2}{*}{$\mathrm{n}$} & \multicolumn{2}{|c|}{ Antenatal care } & \multicolumn{2}{|c|}{ Delivery care } & \multicolumn{2}{|c|}{ Neonatal care } \\
\hline & & Crude OR $(95 \% \mathrm{CI})$ & $\begin{array}{c}\text { Adjusted OR } \\
(95 \% \mathrm{CI})\end{array}$ & $\begin{array}{l}\text { Crude OR } \\
(95 \% \mathrm{CI})\end{array}$ & $\begin{array}{l}\text { Adjusted OR } \\
(95 \% \mathrm{CI})\end{array}$ & $\begin{array}{l}\text { Crude OR } \\
(95 \% \mathrm{CI})\end{array}$ & $\begin{array}{c}\text { Adjusted OR } \\
(95 \% \mathrm{CI})\end{array}$ \\
\hline \multicolumn{8}{|l|}{ Workplace } \\
\hline National hospital & 39 & 1.00 & 1.00 & 1.00 & 1.00 & 1.00 & 1.00 \\
\hline Prefectural hospital & 38 & $9.35(2.30-29.19)^{* *}$ & $7.52(2.29-24.73)^{* *}$ & $2.86(1.12-7.35)^{*}$ & $2.54(0.95-6.79)$ & $5.71(2.11-15.45)^{* *}$ & $4.35(1.53-12.39)^{* *}$ \\
\hline Soum hospital & 16 & $0.97(0.17-5.61)$ & $0.79(0.12-5.02)$ & $0.27(0.07-1.10)$ & $0.23(0.05-0.986)^{*}$ & $0.22(0.03-1.92)$ & $0.16(0.02-1.46)$ \\
\hline \multicolumn{8}{|l|}{$\begin{array}{l}\text { Length of clinical } \\
\text { experience (years) }\end{array}$} \\
\hline 15 & 35 & 1.00 & 1.00 & 1.00 & 1.00 & 1.00 & 1.00 \\
\hline $16-19$ & 20 & $1.09(0.36-3.30)$ & $1.11(0.31-4.05)$ & $0.92(0.30-2.77)$ & $0.67(0.20-2.28)$ & $1.06(0.35-3.18)$ & $0.82(0.23-2.90)$ \\
\hline $20 \leq$ & 38 & $0.20(0.06-0.64)^{* *}$ & $0.26(0.07-0.94)^{*}$ & $0.61(0.24-1.53)$ & $0.62(0.21-1.80)$ & $0.24(0.08-0.69)^{* *}$ & $0.24(0.07-0.81)^{*}$ \\
\hline
\end{tabular}

${ }^{*} \mathrm{p}<0.05,{ }^{* *} \mathrm{p}<0.01$.

per 1000 people in a land area about 333 times the size of Ulaanbaatar [2]. As a result of having more doctors around and of the resulting division of tasks between occupations, nurses and midwives at national hospitals may have fewer opportunities to practice and develop their PA ability on the job, though they are supposed be the best-versed in maternal care. Prefectural hospitals outside Ulaanbaatar, in contrast, have to care for $40 \%$ of all the childbirths in Mongolia [2] while lacking adequate assistance from doctors. In this situation, nurses and midwives are often forced to diagnose and provide treatment throughout the perinatal and neonatal period, which naturally improves their PA abilities due to frequent practice.

Similar to the prefectural hospitals, soum hospitals, which are scattered around the country, also lack doctors. However, the nurses and midwives in the 288 soum hospitals take care of only $14.8 \%$ of all the childbirths in Mongolia [2]; thus, they do not frequently practice PA on the job and consequently have not increased their PA abilities much. Regarding the association between clinical experience and knowledge, a study conducted in Japan by Yamauchi [4], from which we adapted our methods for assessing PA ability, suggested that nurses with more experience are more knowledgeable about PA skills because they learn PA skills on the job. We therefore think that the frequency of exposure to cases, which cannot be fully measured by time on the job, may be influential on PA abilities, as the group among midwives with shorter experience had higher PA scores. The higher MMR in soum hospitals ( 158.6 per 100,000 births) than in national and prefectural hospitals [2] indicates that maternal deaths occur more frequently during labor in soum hospitals. Thus, training for nurses and midwives in peripheral areas should be given priority.

Only $20 \%-40 \%$ of nurses and midwives in national and soum hospitals rated themselves "able to perform alone" on critical PA items such as genital bleeding, uterine contraction, and obstetric shock, all of which could lead to maternal death. This result implies that nurses and midwives in national and soum hospitals, who are responsible for the care of mothers and babies, nevertheless have inadequate skills and knowledge, even in emergency settings. According to an ethnographic and epidemiological study on maternal death in Mongolia from 1996-1998, 36\% of deaths could be attributed to poor antenatal care and about $20 \%$ to mistakes in handling the emergency made by the doctor or midwife [5]. The results of our study suggest that this situation persists even close to a decade later. The fact that longer clinical experience did not influence PA ability (or influenced it negatively in the case of midwives) predicts that the same causes of maternal death may still be seen in the future. In order to prevent maternal deaths, ensuring access to skilled attendance at birth with timely access to effective emergency obstetric care in the event that a complication arises is key [6,7]. Fortunately, adequate access to hospital-based medical services has already been addressed in Mongolia, as a major legacy of the former socialist system [8]. However, while the government's efforts to reduce maternal mortality, conducted with the assistance of international organizations, have been reasonably successful [9], the abilities of the Mongolian nurses and midwives who play a big part in the efforts are still insufficient. In other words, there is a crucial delay - the last of the three delays identified by the charity Maternity Worldwide, in partnership with the Making Pregnancy Safer initiative of the World Health 
Organization to save pregnant women(decision to seek care; identifying and reaching medical facilities; and receipt of adequate and appropriate treatment) $[10,11]$. Among the three delays, the third is crucial, because it would be useless to facilitate access to a health facility if it was not providing quality care [12]. Hill et al. [8] highlighted the bloat and inefficiency of the hospitalbased workforce in Mongolia, a situation that has come about as a result of unrestricted access to medical training and unregulated specialization. Although nurses and midwives in Mongolia are now required to update their licenses and receive 30 credits of nursing education every five years, the system still seems to function poorly. As Yoshino, Surenkholoo, and Yabashi [13] have pointed out, one of the difficulties faced in maintaining a nursing license in Mongolia is limited access to continuing education because of geographical and infrastructural barriers. To help address this issue, Yoshino et al. developed an e-learning system as an example of an effective training tool for nurses and midwives distributed across vast geographical distances [13]. This system has the potential to be effective if nurses and midwives have the necessary IT skills, equipment, and Internet access. To overcome the third delay, continuous in-service training for nurses and midwives in both peripheral areas and specialized hospitals in the capital city, as well as individual ambition to excel on the part of these professionals, are needed.

If there is indeed no significant difference between nurses and midwives in terms of PA ability, then this may also be an issue, because midwives are expected to be equipped with higher PA abilities than nurses in maternal care. Since a midwife's tasks and responsibilities seem to differ between the three hospital levels, a stratified analysis with more participants will be needed to evaluate actual differences between nurses' and midwives' PA abilities. In addition, in future research, actual PA ability needs to be assessed objectively by researchers rather than through self-ratings. Finally, identifying the factors that influence PA ability on each item, and not aggregate ability, should be another priority for future studies.

\section{CONCLUSION}

This study revealed that maternal deaths in the perinatal period have occurred in health facilities lacking adequate and appropriate treatment by skilled birth attendant. Neither working at specialized maternity hospitals nor working longer positively influenced PA ability. However, frequent experience with maternal care procedures seemed to be effective. In order to bring Mongolian MMRdown to a level comparable with those of developed countries, enhancement of in-service training for nurses and midwives, both in peripheral areas and in the capital city, is needed.

\section{ACKNOWLEDGEMENTS}

We are very thankful to the members of the Mongolian Nurses Association who collected the data for this study from various soum hospitals. We are also grateful to Dr. Koji Tamakoshi, Dr. Etsuko Kajita, and Dr. Asako Okamoto from Nagoya University Graduate School of Medicine, who provided academic advice on the research process.

The authors declare that they have no conflicts of interest with respect to the authorship and/or publication of this article.

The authors also disclose the receipt of financial support for the research and/or authorship of this article from the Yuasa International Foundation, Japan.

\section{REFERENCES}

[1] United Nations Statistics Division (2011) Millennium development goals indicators, Mongolia: Trends in maternal mortality: 1990-2008. http://mdgs.un.org/unsd/mdg/Data.aspx

[2] Ministry of Health, National Center for Health Development (2007) Health indicators 2007. Government of Mongolia, Ulaanbaatar.

[3] World Health Organization, UNFPA, UNICEF, AMDD (the Averting Maternal Death and Disability Programme of Columbia University) (2009) Monitoring emergency obstetric care: A handbook. World Health Organization, Geneva.

[4] Yamauchi, T. (2001) Correlation between work experiences and physical assessment in Japan. Nursing and Health Sciences, 3, 213-224. doi:10.1046/j.1442-2018.2001.00091.x

[5] Janes, C.R. andChuluundorj, O. (2004) Free markets and dead mothers: The social ecology of maternal mortality in post-socialist Mongolia. Medical Anthropology Quarterly, 18, 230-257. doi:10.1525/maq.2004.18.2.230

[6] Department for International Development (2004) Reducing maternal deaths: Evidence and action. A strategy for DFID. Government of the United Kingdom, Glasgow.

[7] United Nations Population Fund (n.d.) Safe motherhood. Stepping up efforts to save mother's lives. http://www.unfpa.org/public/home/mothers

[8] Hill, P.S., Dodd, R. andDashdorj, K. (2006) Health sector reform and sexual and reproductive health services in Mongolia. Reproductive Health Matters, 14, 91-100. doi:10.1016/S0968-8080(06)27226-4

[9] Yadamsuren, B., et al. (2010) Tracking maternal mortality declines in Mongolia between 1992 and 2007: The importance of collaboration. Bulletin of the World Health Organization, 88, 192-198. doi:10.2471/BLT.08.061747

[10] Maternity Worldwide (n.d.) The 3 delays model. http://www.maternityworldwide.org/about-us/information -and-resources/the-3-delays-model

[11] Thaddeus, S. And Maine, D. (1994) Too far to walk: Maternal mortality in context. Social Science and Medicine, 38, 1091-1110. doi:10.1016/0277-9536(94)90226-7

[12] UNFPA (n.d.) Emergency obstetric care: Reducing lifethreatening delays. 
http://www.unfpa.org/public/home/mothers/pid/4385

[13] Yoshino, Y., Surenkholoo, A. and Yabashi, Y. (2011) Enhancing maternal and child health nursing competencies via web based continuing education in Mongolia. Proceedings from 2011 Global Health Conference, Global
Health Education Consortium, Canadian Society for International Health, and Consortium of Universities for Global Health, Montreal. 